\title{
Assessment of smoking status based on cotinine levels in nasal lavage fluid
} Mehmet Hakan Ozdener*1, Karen K Yee ${ }^{1}$, Ryan McDermott ${ }^{1}$, Beverly J Cowart ${ }^{1,2}$, Aldona A Vainius ${ }^{1}$, Pamela Dalton ${ }^{1}$ and Nancy E Rawson 1,3

\author{
Address: ${ }^{1}$ Monell Chemical Senses Center, Philadelphia, Pennsylvania, USA, ${ }^{2}$ Dept Otolaryngology, Head-Neck Surgery, Thomas Jefferson \\ University, Philadelphia, Pennsylvania, USA and 'WellGen, Inc, North Brunswick, New Jersey, USA \\ Email: Mehmet Hakan Ozdener* - hozdener@yahoo.com; Karen K Yee - karenyee@monell.org; Ryan McDermott - rmcdermott@monell.org; \\ Beverly J Cowart - cowart@monell.org; Aldona A Vainius - alvainius@ hotmail.com; Pamela Dalton - pdalton@pobox.upenn.edu; \\ Nancy E Rawson - rawson@monell.org \\ * Corresponding author
}

\section{Published: 3 July 2009}

Tobacco Induced Diseases 2009, 5:1I doi:10.1186/1617-9625-5-11
Received: 14 April 2009

Accepted: 3 July 2009

This article is available from: http://www.tobaccoinduceddiseases.com/content/5/I/II

(C) 2009 Ozdener et al; licensee BioMed Central Ltd.

This is an Open Access article distributed under the terms of the Creative Commons Attribution License (http://creativecommons.org/licenses/by/2.0), which permits unrestricted use, distribution, and reproduction in any medium, provided the original work is properly cited.

\begin{abstract}
Cotinine is a principal metabolite of nicotine with a substantially longer half-life, and cotinine levels in saliva, urine or serum are widely used to validate self-reported smoking status. The nasal cavity and olfactory system are directly exposed to tobacco smoke in smokers and in non-smokers who live with or work around smokers. However, despite the potential for a direct impact of tobacco smoke on the nasal epithelium and olfactory neurons, no prior studies have assessed cotinine levels in nasal mucus. We sought to determine whether cotinine levels in nasal lavage fluid (NLF) would provide a reasonable estimate of smoke exposure. We assayed cotinine using a competitive immunoassay in NLF from 23 smokers, 10 non-smokers exposed to tobacco smoke (ETS) and 60 non-smokers who did not report smoke exposure. NLF cotinine levels were significantly higher in smokers than in non-smokers, regardless of their exposure to ambient tobacco smoke. Cotinine levels in this small group of exposed non-smokers were not significantly different than those of nonexposed non-smokers. A cutoff of I ng/ml provided a sensitivity of $91 \%$ and a specificity of $99 \%$ for smoking status in this sample. Data were consistent with self-reported smoking status, and a cutoff of $1.0 \mathrm{ng} / \mathrm{ml} \mathrm{NLF}$ cotinine may be used to classify smoking status. While saliva is the most easily obtained body fluid, NLF can be used to provide an objective and precise indication of smoking status and more directly reflects smoke exposure in the nasal and olfactory mucosa.
\end{abstract}

\section{Introduction}

Precise estimation of direct exposure to tobacco smoke is a problem for epidemiologic studies due to human errors and inaccuracy in self report. Assessment of passive exposure to tobacco smoke is even more problematic $[1,2]$. While nicotine has a relatively short half-life of about 2 hours, cotinine, a principal metabolite of nicotine, has a half-life of approximately 20 hours, and is a specific and sensitive marker for determining exposure to tobacco [35]. Therefore, measurement of salivary, urinary or serum cotinine values have been used to validate self-reported smoking status $[1,4]$, with saliva providing the most easily obtained source [6-8]. 
Notably, the olfactory sensory neuroepithelium and nasal mucosa are directly exposed to tobacco smoke in both smokers and non-smokers who live with or work around smokers. Smoking has been shown to reduce olfactory sensitivity in a dose- and time-dependent manner [9-12], and passive smoke exposure has been implicated in reduced olfactory function as well [13]. Using nicotine nasal spray caused adverse effects of nasal irritation and burning and taste and smell complaints [14]. Moreover, both exposures to tobacco smoke and to lipopolysaccharide, an active component of cigarette smoke, trigger a dramatic increase in the degree of olfactory neuron apoptosis $[15,16]$.

The impact of smoking on the nasal mucosa has received considerably less study than its impact on lower respiratory tissue. Nonetheless, there is evidence for multiple deleterious effects, including increased nasal resistance, decreased mucociliary flow and mucosal sensitivity, and induces increase in DNA adduct and may cause nasal tumors due to numerous chemicals found $[17,18]$. Histopathological analysis of nasal mucosa obtained from rats exposed to tobacco smoke revealed a decrease in the extent of olfactory epithelium including loss of cilia and development of metaplasia [19].

Tobacco smoke may exert direct effects on nasal epithelial health and olfactory neuronal function, and proteomic analysis has demonstrated altered protein levels in the nasal lavage fluid (NLF) of smokers [20], yet no prior studies have assessed cotinine levels in nasal mucus. Basic information concerning cotinine levels in the NLF of individuals with varying degrees of exposure to tobacco smoke is of clinical importance for studies evaluating the impact of tobacco smoke on nasal and olfactory pathophysiology, as well as in other situations where a noninvasive sample is desired and saliva is not available or reliable. Therefore, we sought to determine whether cotinine levels in NLF would provide a reasonable estimate of smoke exposure. Our results indicate that NLF cotinine was significantly higher in smokers than in nonsmokers and established a cut of $1.0 \mathrm{ng} / \mathrm{ml}$ that may be used in future studies as an objective indicator of current smoking.

\section{Materials and methods \\ Participants}

Individuals $(\mathrm{n}=97)$ who self-reported good general health participated. All were asked to complete a questionnaire regarding their smoking status (current smoker, past smoker, and non-smoker), smoking history (number of cigarettes or cigars smoked per day), smoking duration (years), if a past smoker, years since quitting, and ambient smoke exposure (type and duration). Four participants were excluded from the analyses: 2 provided inconsistent/ incomplete information regarding their smoking habits, and 2 reported having recently quit smoking, and thus did not clearly fall into any of the smoking status groups described below. The remaining participants included 41 females and 52 males; their mean age was $36.1 \pm 11.9$ years (range 18-64 years).

\section{Questionnaire content}

We used detail questionnaires to determine smoking status of subjects. Questions covered age, sex, smoking history, for smokers only, the number of cigarettes smoked per day, pipe or cigar smoking, number of years as a regular smoker. For non-smokers, when did you quit? How long did you smoke and what did you smoke? Exposure to environmental tobacco smoke was assessed by the following questions: "Who is currently a smoker, among people around you?"; "Do you live with someone who smokes? (Yes/No)"; and "In work place buildings, are you exposed to other people's tobacco smoke? (Yes/No).

\section{Smoking status groups \\ Smoker}

Twenty-three subjects ( 8 females, 15 males) reported themselves to be current smokers. Active smokers consumed between 1 and 20 cigarettes/day at the time of assessment. Their mean age was $32.3 \pm 9.1$ years (range 21-64).

\section{Non-smoker non-exposed}

Sixtysubjects ( 27 females, 33 males) reported themselves to be non-smokers with a minimal history of ambient exposure to cigarette smoke. If prior smokers, the nonsmokers had not smoked for at least 6 months and were not subject to substantial exposure to tobacco smoke in public or private surroundings. Their mean age was $37.9 \pm$ 12.5 years (range $21-63$ ).

\section{Non-smoker exposed to tobacco smoke (ETS)}

Ten passive smokers ( 6 females, 4 males) were defined by self-reported significant exposure to smoke in public buildings or private surroundings on a regular basis. Their mean age was $34.0 \pm 12.2$ years (range $18-53$ ).

\section{Collection of nasal lavage fluid}

Subjects were given a sterilized metered-pump aerosolizer filled with $0.1 \mathrm{M}$ sterile phosphate buffer solution without calcium or magnesium. Each pump action delivered 100 $\mu \mathrm{l}$ of solution ( $4 \mathrm{ml}$ total per nostril). They were asked to spray and sniff 4-5 times into one nostril while occluding the other nostril, then to forcibly expel the nasal contents into a glass container. Collected NLF was then centrifuged at $9000 \mathrm{rpm}$ for 10 minutes and the supernatant frozen at $-20^{\circ} \mathrm{C}$. Freezing NLF samples precipitates the mucins. On the day of the assay, samples were thawed completely, vortexed and centrifuged at $1500 \times \mathrm{g}(@ 3000 \mathrm{rpm})$ for 15 
minutes. Samples were at room temperature before being added to the assay plate.

\section{Immunoassay of Cotinine concentration}

To determine cotinine levels in NLF, High Sensitivity Salivary Cotinine Quantitative enzyme immunoassay kit (Cat. \# 1-2112) from The Salimetrics ${ }^{\mathrm{TM}}$ was used according to manufacturer's instructions with slight modification. The test principle for this kit is based on the competition of cotinine for antibody binding sites. The cotinine in samples and peroxidase-labeled cotinine compete; therefore the amount of antibody bound to the plate is inversely proportional to the cotinine concentration.

Briefly, $20 \mu \mathrm{L}$ of controls (blank and standards) and samples were pipetted into appropriate wells. First, enzyme conjugate and, second, antiserum were added and incubated for 1.5 hours at $37^{\circ} \mathrm{C}$ with constant mixing at 500$600 \mathrm{rpm}$. At the end of the incubation period, 3,3',5,5' Tetramethylbenzidine (TMB) solution was added and mixed at $500 \mathrm{rpm}$ for 5 minutes and then incubated in the dark for an additional 25 minutes at room temperature. The reaction was quenched by adding stop solution using a multi-channel pipette, followed by mixing on a plate rotator at room temperature for 3 minutes at $500 \mathrm{rpm}$ (or until the color turned from green to yellow). The activity of the peroxidase was determined by a distinct development of colors and detected by $450 \mathrm{~nm}$ extinction measurement with TMB substrate. The plate was read within 10 minutes of adding stop solution. These analyses took place at a room temperature between 20 and $25^{\circ} \mathrm{C}$. Average optical density (OD) was calculated by subtracting the average OD for the non-specific binding wells from the average $\mathrm{OD}$ of the zero standards, controls, and unknowns. The percent bound $(\mathrm{B} / \mathrm{Bo})$ for each standard $(200 \mathrm{ng} / \mathrm{mL}, 66.7 \mathrm{ng} / \mathrm{mL}, 22.2 \mathrm{ng} / \mathrm{mL}, 7.4 \mathrm{ng} / \mathrm{mL}, 2.5 \mathrm{ng} /$ $\mathrm{mL}$, and $0.8 \mathrm{ng} / \mathrm{mL}$ ), control, and unknown was calculated by dividing the average OD (B) by the average OD for the zero (Bo). Final OD was converted to $\mathrm{ng} / \mathrm{ml}$.

\section{Statistical analysis}

All analyses were performed using Systat ${ }^{\circledast}$, version 11.00.01. Cotinine levels were not normally distributed (Shapiro-Wilk statistic $=0.54, \mathrm{p}<0.001$ ). Therefore, pair wise comparisons between groups (smoking status and gender) were made using the non-parametric Kolmogorov-Smirnov Two Sample test. The Spearman correlation was used to assess the relationship between smoking frequency and NLF cotinine in smokers.

\section{Results}

NLF cotinine levels ranged from $0.08 \mathrm{ng} / \mathrm{ml}$ to $11.73 \mathrm{ng} /$ $\mathrm{ml}$ and averaged 7.5 times higher in smokers than in nonsmokers. The median cotinine concentration in the NLF of non-smokers was $0.65 \mathrm{ng} / \mathrm{ml}(0.08 \mathrm{ng} / \mathrm{ml}$ to $0.90 \mathrm{ng} /$ $\mathrm{ml})$, of passive smokers $0.64 \mathrm{ng} / \mathrm{ml}(0.54 \mathrm{ng} / \mathrm{ml}$ to 1.02 $\mathrm{ng} / \mathrm{ml})$ and of active smokers $4.78 \mathrm{ng} / \mathrm{ml}(0.90 \mathrm{n} / \mathrm{ml}$ to $11.73 \mathrm{ng} / \mathrm{ml}$ ); the percentile distributions of levels in each group are given in Table 1. Cotinine levels were significantly higher in the NLF of smokers than of that of either non-smokers non-exposed ( $p<0.001$ ) or non-smokers ETS $(\mathrm{p}<0.001)$ (Figure 1). There was, however, no significant difference in cotinine levels between the latter two groups. Although others have reported differences between non-smokers non-exposed and non-smokers ETS in cotinine levels in serum, saliva and urine [21-25], this is not a consistent finding, and there tends to be considerable overlap between these groups $[5,24,25]$, probably reflecting, in part, difficulties in quantifying environmental smoke exposure.

Among non-smoking non-exposed subjects, there was a small but significant difference between females and males, with females showing slightly lower cotinine levels, as has been reported by others $[23,26]$. However, no significant gender difference was observed in our smaller groups of passive or active smokers, nor was there a gender difference among smokers in reported frequency of smoking.

There was a significant correlation ( rho $=0.48, \mathrm{p}<0.02$ ) between reported frequency of cigarette use and measured NLF cotinine levels in smokers (Figure 2). This is consistent with reports of cotinine levels in saliva and serum $[27,28]$. Of note, cotinine levels observed in the two participants excluded from the general analyses who reported recent abstinence from smoking ( $<3$ months) were consistent with, or higher than, their reports of prior usage ( 1 cigarette/week, cotinine $=1.54 \mathrm{ng} / \mathrm{ml} ; 20$ cigarettes/day, cotinine $=8.37 \mathrm{mg} / \mathrm{ml}$ ), suggesting either unreported use of nicotine containing products, misreport of current usage or slow clearance of cotinine in the nasal mucous.

Based on self-reported smoking status, we estimated the lowest concentration of cotinine as a cutoff point to distinguish nonsmokers from smokers. The distributions of NLF cotinine in smokers and nonsmokers (exposed and not exposed) overlapped in few subjects. The value of 1 $\mathrm{ng} / \mathrm{mL}$ represented the best combined levels of sensitivity (91\%) and specificity (99\%) (Figure 3). The sum of sensitivity and specificity changed little for cutoff values between $1 \mathrm{ng} / \mathrm{ml}$ (sensitivity, 91\%; specificity, 99\%) and $2 \mathrm{ng} / \mathrm{ml}$ (sensitivity, 74\%; specificity, 100\%). Similar cutoff levels were obtained in men and women (not shown). NLF cotinine levels lower than $1 \mathrm{ng} / \mathrm{mL}$ were observed in $100 \%$ of the self-reported non-exposed nonsmokers and in more than $90 \%$ of self-reported nonsmokers ETS. In smokers, fewer than 10 percent of smokers had levels lower than $1 \mathrm{ng} . / \mathrm{ml}$. 

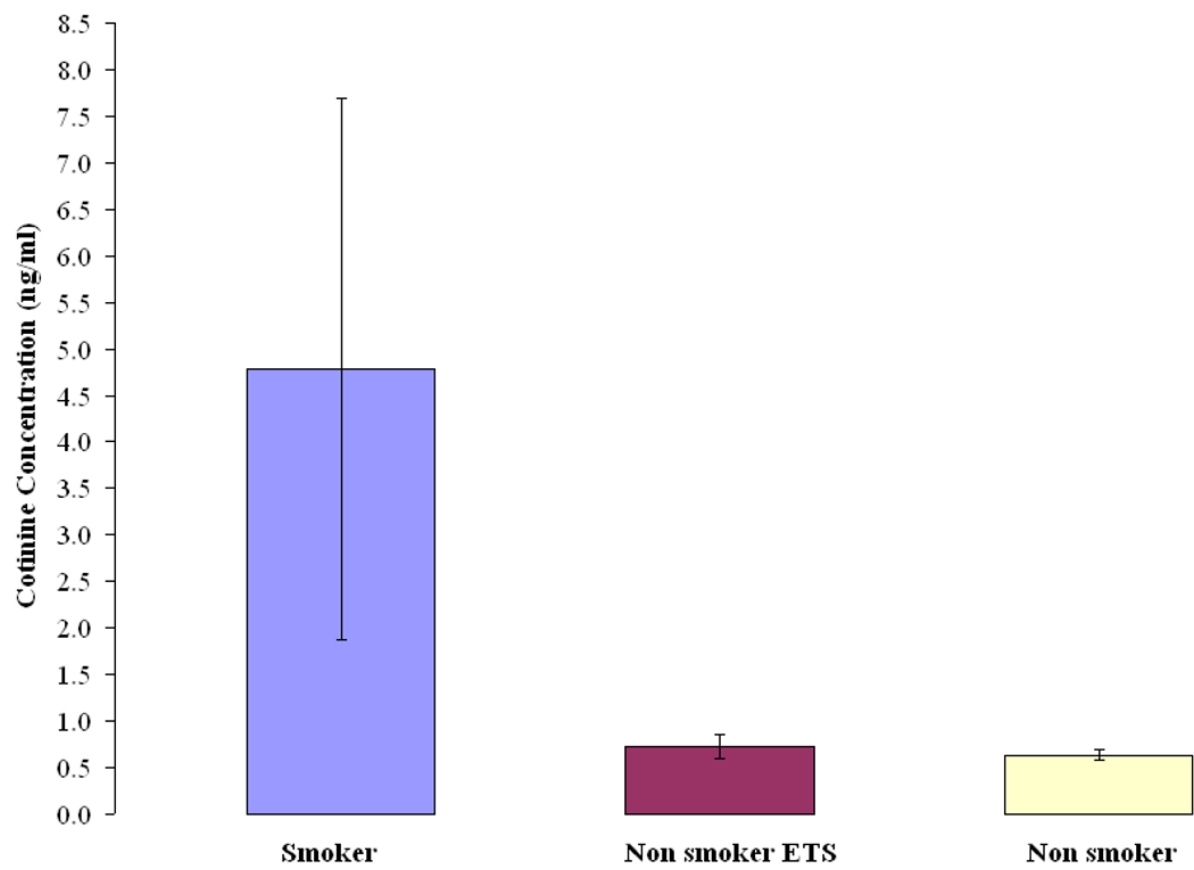

Figure I

Cotinine level is of indicator smoking status. The median cotinine concentration in the NLF of non-smokers was 0.65 ng/ $\mathrm{ml}$, of passive smokers $0.64 \mathrm{ng} / \mathrm{ml}$ and of active smokers $4.78 \mathrm{ng} / \mathrm{ml}$. Cotinine levels were significantly higher in the NLF of smokers than of that of either non-smokers non-exposed $(p<0.00 \mathrm{I})$ or non-smokers ETS $(p<0.00 \mathrm{I})$. No significant difference in cotinine levels between the non-smoker and nonsmoker ETS groups.

\section{Discussion}

The effects of tobacco smoke on the xenobiotic enzymes (cytochrome P-450 system) in the olfactory tissues are of particular interest because nasal tissues, in particular, olfactory epithelium, are an initial contact site with inhaled toxicants. Nicotine is rapidly metabolized to cotinine via the cytochrome P450 pathway, which is active within cells in both the nasal and olfactory epithelia. In humans nicotine is mainly converted to cotinine by cytochrome P450 (CYP2A) in human olfactory epithelium [29]. Previous studies demonstrated that cotinine levels may vary in body fluids in relation to differences in exposure and the activity of xenobiotic metabolizing enzymes in different tissues and organs $[10,15]$. The time course of nicotine in the body organs and resultant pharmacologic effects are highly dependent on the route and rate of dosing. Nicotine accumulation is age-dependent and is quantitatively different in various segments in the mouse brain [30]. Nicotine also accumulates markedly in different body fluids such gastric fluid, saliva and breast milk. Comparison of these gastric fluid/plasma, saliva/plasma and milk/plasma ratio was found different depend on administration route $[31,32]$. Additionally, changes in the expression of nasal xenobiotic metabolizing enzymes due to tobacco smoke may have a role in the development of deficits in olfactory performance. Interestingly, xenobiotic-metabolizing enzymines of the nasal mucosae may be regulated differently than other tissues [33].

Table I: The percentile distributions of cotinine levels in NLF

\begin{tabular}{|c|c|c|c|c|c|c|c|c|}
\hline Self-reported smoking habit & $\mathbf{N}$ & Min & I0th & 25th & 50th & 75th & $90^{\text {th }}$ & Max \\
\hline Nonsmokers & 60 & 0.00 & 0.56 & 0.59 & 0.65 & 0.71 & 0.76 & 0.90 \\
\hline Nonsmokers ETS & 10 & 0.54 & 0.59 & 0.60 & 0.64 & 0.86 & 0.98 & 1.02 \\
\hline Smokers & 23 & 0.9 & 1.11 & 1.70 & 4.27 & 7.51 & 10.41 & 11.73 \\
\hline
\end{tabular}




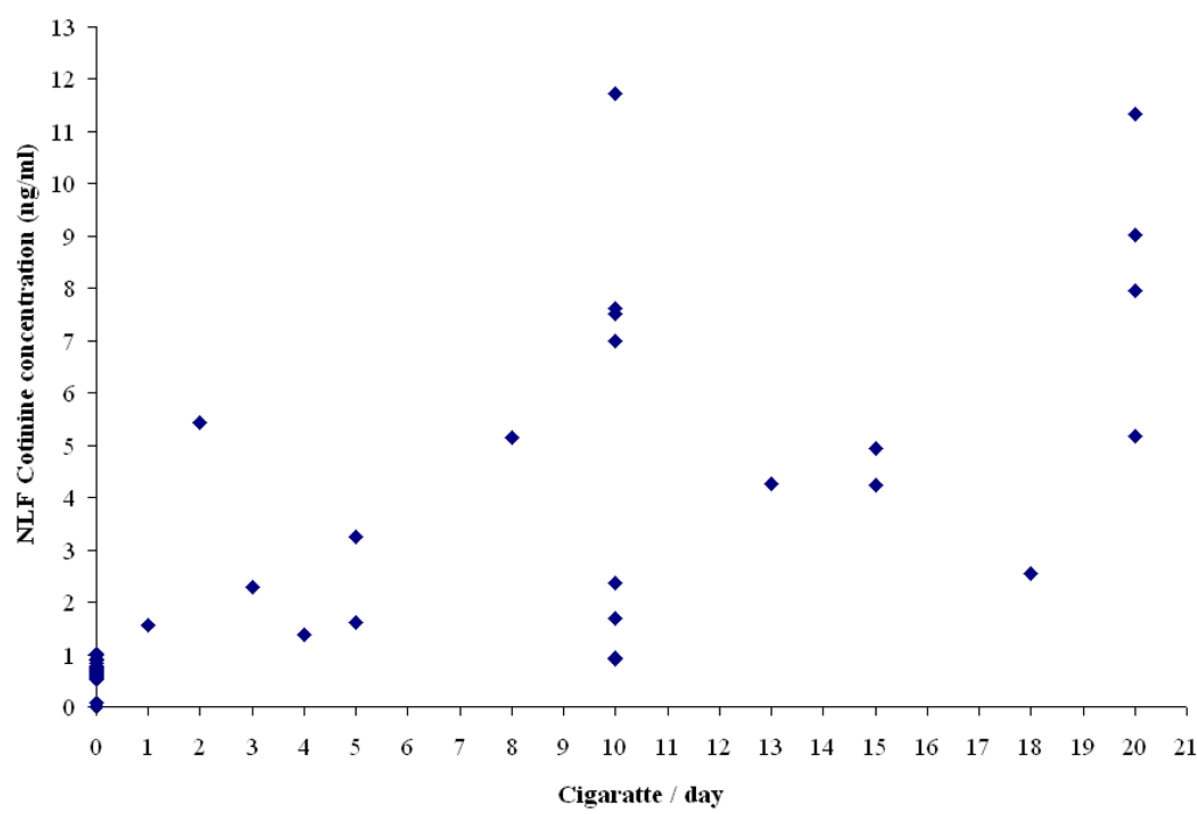

Figure 2

Association between the concentration of NLF cotinine and the number of cigarettes reported to be smoked daily. Significant correlation was found between reported frequency of cigarette use and measured NLF cotinine levels in smokers.

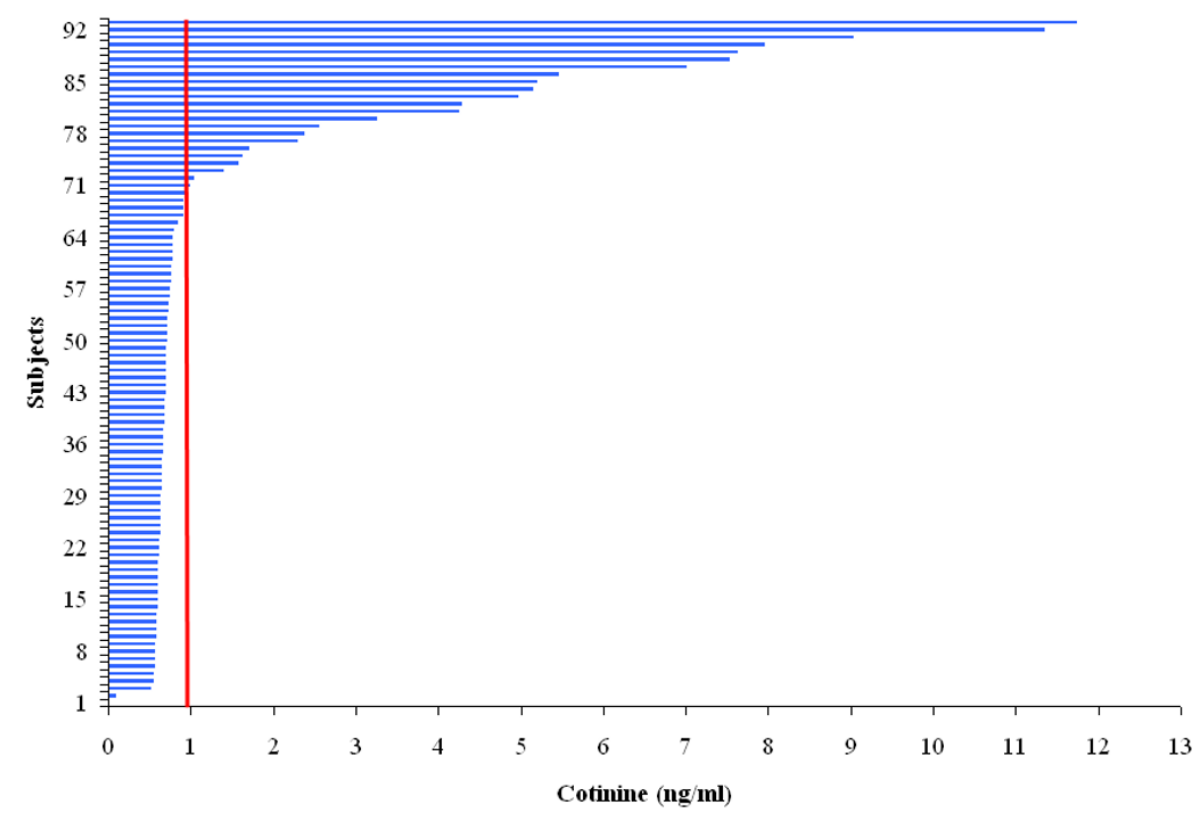

Figure 3

Distribution of NLF cotinine across all subjects. NLF cotinine level of I $\mathrm{ng} / \mathrm{mL}$ was lowest concentration as a cutoff point to distinguish nonsmokers from smokers with the best combined levels of sensitivity $(91 \%)$ and specificity $(99 \%)$. Similar cutoff levels were obtained in men and women (not shown). NLF cotinine levels lower than I $\mathrm{ng} / \mathrm{mL}$ were observed in $100 \%$ of the self-reported non-exposed nonsmokers and in more than $90 \%$ of self-reported nonsmokers ETS. 
Thus, differences in the levels of cotinine in the nasal mucus may reflect both exposure to nicotine and the ability of the nasal detoxification system to metabolize this xenobiotic chemical. Two major biomarkers for assessment of smoking status, nicotine and cotinine can be measured in various biological samples, and can be assayed using gas or liquid chromatography, radioimmunoassay (RIA) or enzyme immunoassays (ELISA) [34-37]. However, there has been no report of the whether cotinine can be assayed in NLF, and if so, whether levels reflect smoking status of the subject with sufficient accuracy for use in confirmation of smoking status. Our data provide a reliable protocol and reference criteria for assignment of smoking status based on cotinine levels in nasal lavage fluid. In conclusion, NLF cotinine can be a reliable biomarker of clinical importance in studies evaluating the impact of nicotine exposure on nasal and olfactory pathophysiology, as well as in other situations where saliva is not available and an objective indicator of smoking status is needed.

\section{Abbreviations}

NLF: Nasal lavage fluid; ETS: Exposed totobacco smoke.

\section{Competing interests}

The authors declare that they have no competing interests.

\section{Authors' contributions}

MHO carried out most of experiments and drafted the manuscript. KKY, RM and AAV participated in the design of the study and collected samples. PD and BJC helped to organize and analyze the data and edit the manuscript. NER initiated and managed the project and coordinated and edited the manuscript. All authors read and approved the final manuscript.

\section{Acknowledgements}

This work was supported in part by grant DC006760 from the National Institute on Deafness and Other Communication Disorders.

\section{References}

I. Gan WQ, Cohen SB, Man SF, Sin DD: Sex-related differences in serum cotinine concentrations in daily cigarette smokers. Nicotine Tob Res 2008, I 0: I 293-1300.

2. Malaiyandi V, Sellers EM, Tyndale RF: Implications of CYP2A6 genetic variation for smoking behaviors and nicotine dependence. Clin Pharmacol Ther 2005, 77:145-I58.

3. Benowitz NL: Biomarkers of environmental tobacco smoke exposure. Environ Health Perspect 1999, I 07(Suppl 2):349-355.

4. Perez-Stable EJ, Benowitz NL, Marin G: Is serum cotinine a better measure of cigarette smoking than self-report? Prev Med 1995, 24: $17 \mid-179$

5. Seong MW, Nam MH, Ryu HJ, Kong SY, Myung SK, Seo HG, et al:: The comparison of two smoking biomarkers in various biological samples. Clin Chim Acta 2007, 383:180-I8I.

6. Abrams DB, Follick MJ, Biener L, Carey KB, Hitti J: Saliva cotinine as a measure of smoking status in field settings. Am J Public Health 1987, 77:846-848.

7. Beckett $\mathrm{AH}$, Triggs Ej: Determination of nicotine and its metabolite, cotinine, in urine by gas chromatography. Nature 1966, 21 I:1415-1417.
8. Wald NJ, Idle M, Boreham J, Bailey A, Van Vunakis H: Urinary nicotine concentrations in cigarette and pipe smokers. Thorax 1984, 39:365-368.

9. Frye RE, Schwartz BS, Doty RL: Dose-related effects of cigarette smoking on olfactory function. JAMA 1990, 263: I233-I 236.

10. Ishimaru T, Fujii M: Effects of smoking on odour identification in Japanese subjects. Rhinology 2007, 45:224-228.

II. Katotomichelakis M, Balatsouras D, Tripsianis G, Davris S, Maroudias $\mathrm{N}$, Danielides $\mathrm{V}$, et al.: The effect of smoking on the olfactory function. Rhinology 2007, 45:273-280.

12. Vennemann MM, Hummel T, Berger K: The association between smoking and smell and taste impairment in the general population. J Neurol 2008, 255: I I 2I-I I 26.

13. Nageris $B$, Hadar T, Hansen MC: The effects of passive smoking on olfaction in children. Rev Laryngol Otol Rhinol (Bord) 2002, | 23:89-9|.

14. Rubinstein ML, Benowitz NL, Auerback GM, Moscicki AB: A randomized trial of nicotine nasal spray in adolescent smokers. Pediatrics 2008, I 22:e595-e600.

15. Vent J, Bartels S, Haynatzki G, Gentry-Nielsen MJ, Leopold DA, Hallworth R: The impact of ethanol and tobacco smoke on intranasal epithelium in the rat. Am J Rhinol 2003, I 7:24I-247.

16. Yagi S, Tsukatani T, Yata T, Tsukioka F, Miwa T, Furukawa M: Lipopolysaccharide-induced apoptosis of olfactory receptor neurons in rats. Acta Otolaryngol 2007, I 27:748-753.

17. Phillips DH: Smoking-related DNA and protein adducts in human tissues. Carcinogenesis 2002, 23:1979-2004.

18. Zhu BQ, Heeschen C, Sievers RE, Karliner JS, Parmley WW, Glantz SA, et al: Second hand smoke stimulates tumor angiogenesis and growth. Cancer Cell 2003, 4:191-196.

19. Vent J, Robinson AM, Gentry-Nielsen MJ, Conley DB, Hallworth R Leopold DA, et al:: Pathology of the olfactory epithelium: smoking and ethanol exposure. Laryngoscope 2004, | | 4: | 383-1388

20. Ghafouri B, Stahlbom B, Tagesson C, Lindahl M: Newly identified proteins in human nasal lavage fluid from non-smokers and smokers using two-dimensional gel electrophoresis and peptide mass fingerprinting. Proteomics 2002, 2: I I 2- I 20.

21. Benowitz NL, Bernert JT, Caraballo RS, Holiday DB, Wang J: Optimal serum cotinine levels for distinguishing cigarette smokers and nonsmokers within different racial/ethnic groups in the United States between 1999 and 2004. Am J Epidemiol 2009, 169:236-248.

22. Etter JF, Vu DT, Perneger TV: Saliva cotinine levels in smokers and nonsmokers. Am J Epidemiol 2000, I 5 I:25 |-258.

23. Jarvis MJ, Feyerabend C, Bryant A, Hedges B, Primatesta P: Passive smoking in the home: plasma cotinine concentrations in non-smokers with smoking partners. Tob Control 200I, 10:368-374

24. Seccareccia F, Zuccaro P, Pacifici R, Meli P, Pannozzo F, Freeman KM, et al:: Serum cotinine as a marker of environmental tobacco smoke exposure in epidemiological studies: the experience of the MATISS project. Eur J Epidemiol 2003, 1 8:487-492.

25. Simoni M, Baldacci S, Puntoni R, Pistelli F, Farchi S, Lo PE, et al.: Plasma, salivary and urinary cotinine in non-smoker Italian women exposed and unexposed to environmental tobacco smoking (SEASD study). Clin Chem Lab Med 2006, 44:632-638.

26. Thompson SG, Stone R, Nanchahal K, Wald NJ: Relation of urinary cotinine concentrations to cigarette smoking and to exposure to other people's smoke. Thorax 1990, 45:356-36I.

27. Vine MF, Hulka BS, Margolin BH, Truong YK, Hu PC, Schramm MM, et al: Cotinine concentrations in semen, urine, and blood of smokers and nonsmokers. Am J Public Health 1993, 83: I 335-I 338.

28. Wall MA, Johnson J, Jacob P, Benowitz NL: Cotinine in the serum, saliva, and urine of nonsmokers, passive smokers, and active smokers. Am J Public Health 1988, 78:699-70I.

29. Chen Y, Liu YQ, Su T, Ren X, Shi L, Liu D, et al.: Immunoblot analysis and immunohistochemical characterization of CYP2A expression in human olfactory mucosa. Biochem Pharmacol 2003, 66: $|245-| 25 \mid$.

30. Ilback NG, Stalhandske T: Nicotine accumulation in the mouse brain is age-dependent and is quantitatively different in various segments. Toxicol Lett 2003, I 43: I75-I84.

31. Lindell G, Lunell E, Graffner H: Transdermally administered nicotine accumulates in gastric juice. Eur J Clin Pharmacol 1996, 5I:3|5-3|8. 
32. Luck $\mathrm{W}, \mathrm{Nau} \mathrm{H}$ : Nicotine and cotinine concentrations in serum and milk of nursing smokers. Br J Clin Pharmacol 1984, 18:9-15.

33. Wardlaw SA, Nikula KJ, Kracko DA, Finch GL, Thornton-Manning JR, Dahl AR: Effect of cigarette smoke on CYPIAI, CYPIA2 and CYP2B I/2 of nasal mucosae in F344 rats. Carcinogenesis 1998, 19:655-662.

34. Feyerabend C, Russell MA: Rapid gas-liquid chromatographic determination of cotinine in biological fluids. Analyst 1980, 105:998-1001.

35. Knight GJ, Palomaki GE, Lea DH, Haddow JE: Exposure to environmental tobacco smoke measured by cotinine I25|-radioimmunoassay. Clin Chem 1989, 35:1036-1039.

36. Kuo HW, Yang JS, Chiu MC: Determination of urinary and salivary cotinine using gas and liquid chromatography and enzyme-linked immunosorbent assay. J Chromatogr B Analyt Technol Biomed Life Sci 2002, 768:297-303.

37. Ziegler UE, Kauczok J, Dietz UA, Reith HB, Schmidt K: Clinical correlation between the consumption of nicotine and cotinine concentrations in urine and serum by competitive enzymelinked immunosorbent assay. Pharmacology 2004, 72:254-259.

Publish with Bio Med Central and every scientist can read your work free of charge

"BioMed Central will be the most significant development for disseminating the results of biomedical research in our lifetime. "

Sir Paul Nurse, Cancer Research UK

Your research papers will be:

- available free of charge to the entire biomedical community

- peer reviewed and published immediately upon acceptance

- cited in PubMed and archived on PubMed Central

- yours - you keep the copyright 